\title{
Effects of Nitroglycerin on Transmural Myocardial Blood Flow in the Unanesthetized Dog
}

\author{
Robert J. Bache, Robert M. Ball, Frederick R. Cobb, \\ Judith C. Rembert, and Joseph C. Greenfield, Jr. \\ From the Veterans Administration Hospital, Durham, North Carolina 27705, \\ and the Department of Medicine, Division of Cardiology, Duke University \\ Medical Center, Durham, North Carolina 27710
}

\begin{abstract}
A в S T R A C T This study was designed to determine the effect of nitroglycerin upon transmural distribution of myocardial blood flow in the awake dog during normal conditions and in the presence of ischemia-induced coronary vasodilation. Studies were performed in chronically prepared dogs with electromagnetic flowmeters and hydraulic occluders on the left circumflex coronary artery. Regional myocardial blood flow was estimated by using radionuclide-labeled microspheres, $7-10 \mu \mathrm{m}$ in diameter, injected into the left atrium. During control conditions endocardial flow $(0.86 \pm \mathrm{SEM}$ $0.05 \mathrm{ml} / \mathrm{min}$ per $\mathrm{g}$ ) slightly exceeded epicardial flow $(0.72 \pm 0.03 \mathrm{ml} / \mathrm{min}$ per $\mathrm{g}, P<0.05)$, and this distribution of flow was not significantly altered by nitroglycerin. After a 5-s coronary artery occlusion, reactive hyperemia occurred with excess inflow of arterial blood effecting $360 \pm 15 \%$ repayment of the blood flow debt incurred during occlusion. When arterial inflow was limited to the preocclusion rate during coronary vasodilation after a 5-s total coronary artery occlusion, flow to the subepicardial myocardium was increased at the expense of underperfusion of the subendocardial myocardium, and the delayed reactive hyperemia was markedly augmented (mean blood flow debt repayment $=775 \pm 105 \%, P<0.01)$. These data suggested that subendocardial underperfusion during the interval of coronary vasodilation in the presence of a flow-limiting
\end{abstract}

Presented in part at the 66th Annual Meeting of the American Society for Clinical Investigation, Atlantic City, N. J., 6 May 1974.

Dr. Bache is the recipient of Research Career Development Award 1-K04-HL-00039 from the U. S. Public Health Service. Dr. Cobb is a Clinical Investigator at the Veterans Administration Hospital, Durham, N. C. Dr. Greenfield is the recipient of Research Career Development Award 1K3-HL-28112 from the U. S. Public Health Service.

Received for publication 22 November 1974 and in revised form 10 February 1975. proximal coronary artery stenosis caused continuing subendocardial ischemia which resulted in augmentation of the reactive hyperemic response. In this experimental model both the redistribution of myocardial blood flow which occurred during an interval of restricted arterial inflow after a 5-s coronary artery occlusion and augmentation of the subsequent reactive hyperemic response were returned toward normal by nitroglycerin. This effect of nitroglycerin may have resulted, at least in part, from its ability to vasodilate the penetrating arteries which deliver blood from the epicardial surface to the subendocardium.

\section{INTRODUCTION}

Because cardiac contraction impedes blood flow into the subendocardial myocardium during systole, uniform transmural myocardial perfusion is dependent upon augmentation of subendocardial flow during diastole $(1,2)$. This diastolic perfusion gradient favoring the subendocardium results from active coronary vasomotion, principally at the precapillary level, maintaining diastolic vascular resistance lower within the subendocardium than in the subepicardium (2). Myocardial ischemia, by causing generalized coronary vasodilation, has been shown to compromise this normal gradient of transmural diastolic coronary vascular resistance (3-5). Since ischemia produces coronary vasodilation principally at the precapillary resistive vessels without dilation of the larger "conductive" vessels where nitroglycerin appears to act, it is possible that any redistribution of myocardial blood flow away from the subendocardium effected by ischemic dilation of the precapillary vessels could be modified by dilation of the conductive vessels by nitroglycerin $(6,7)$.

Previous studies have shown that in the presence of a flow-limiting coronary artery stenosis, coronary vaso-

The Journal of Clinical Investigation Volume 55 June 1975.1219-1228

1219 
dilation resulting from ischemia may compromise the ability of active coronary vasomotion to maintain uniform transmural myocardial perfusion. In this situation, subendocardial underperfusion may be perpetuated in the presence of a normal net volume of coronary artery inflow (8). The present study was designed to extend these findings to determine whether nitroglycerin may act to correct this ischemia-induced subendocardial underperfusion and restore transmural myocardial blood flow distribution toward normal. To evaluate the potential mechanisms by which nitroglycerin may affect the distribution of myocardial blood flow during ischemia-induced coronary vasodilation, additional studies tested whether during coronary artery constriction blood flow available to the subendocardium may be increased as a result of a reduction of myocardial oxygen consumption by nitroglycerin, or whether nitroglycerin may increase total coronary inflow by vasodilation of preexisting intercoronary collateral vessels. In addition, the effect of nitroglycerin on transmural myocardial perfusion during unrestricted coronary inflow was studied. All studies were performed in chronically instrumented, unanesthetized dogs to eliminate possible interfering effects associated with general anesthesia and acute surgical trauma.

\section{METHODS}

17 adult mongrel dogs weighing $23-30 \mathrm{~kg}$ were anesthetized with sodium thiamylal $(30-40 \mathrm{mg} / \mathrm{kg}$ i.v. $)$ and underwent left thoracotomy. A polyvinyl chloride heparin-filled catheter $3 \mathrm{~mm}$ in outside diameter was introduced into the arch of the aorta via the left internal mammary artery. A similar catheter was introduced into the left atrial cavity through the left atrial appendage and secured in place with a pursestring suture. The proximal $1.5 \mathrm{~cm}$ of the circumflex branch of the left coronary artery was dissected free and a hydraulic occluder constructed in our laboratory was positioned around the vessel proximal to any branches (9). In 11 dogs a Statham type ST electromagnetic flowmeter probe $^{1}$ was positioned around the left circumflex coronary artery proximal to the hydraulic occluder. Care was taken to attain mechanical stability of the flow probe on the artery to insure a consistently stable baseline during later flow measurements (10). In six of these dogs with coronary flowmeter probes, the ascending aorta was dissected free and a Statham type TTQ flowmeter probe ${ }^{1}$ was placed on the ascending aorta. The catheters, hydraulic occluder tube, and electromagnetic flowmeter leads were tunneled dorsally into a subcutaneous pouch at the base of the neck but were not exteriorized to protect them from damage. The flowmeter leads, catheters, and occluder tube were exteriorized through a $1-\mathrm{cm}$ skin incision with $2 \%$ lidocaine infiltration anesthesia the morning before study. Studies were carried out 13-28 days after the initial surgery when all animals were active and fully recovered from surgery. At the time of study hematocrits were $37-48 \%$. Animals were trained to lie quietly on their right sides during the period of study.

Throughout this report the phrase "coronary blood flow" will denote measurements of flow through the circumflex

${ }^{1}$ Statham Instruments, Inc., Oxnard, Calif. branch of the left coronary artery. Aortic and coronary flows were measured with a Statham M-4000 flowmeter. ${ }^{1}$ Flowmeter calibrations performed by passing measured flows of normal saline through the probes remained within a standard deviation of not more than $\pm 7 \%$ during the period of study. The aortic and left atrial pressures were measured by using pressure transducers. ${ }^{2}$ Lead II of a standard electrocardiogram was obtained. Data were recorded with a Hewlett-Packard model 8800 eight-channel direct-writing oscillograph $^{3}$ and a Hewlett-Packard model 3917-A eightchannel magnetic tape recorder. ${ }^{3}$

The laboratory was dimly illuminated and kept free of noise or other activity which might disturb the dog. Coronary artery occlusions were performed by injecting and holding $1 \mathrm{ml}$ of water into the occluder tubing with a handheld syringe. This technique allowed completed occlusion or complete release of coronary blood flow within less than $0.1 \mathrm{~s}$. After all recording instruments were connected, a 60 -s coronary artery occlusion was produced while lead II of the electrocardiogram was monitored. Only dogs which exhibited significant ST segment elevation, as well as increased heart rate, indicating absence of an effective coronary collateral circulation which might impair the ischemic stimulus produced by coronary occlusion during subsequent studies were used for this study (11). Three of the dogs tested failed to manifest these indications of myocardial ischemia during a 60 -s occlusion and were consequently not used for this study. Subsequently, a 45-60-min interval was allowed for the animal to adjust to the laboratory conditions. During this time data were sampled continuously to insure that a control steady state had been achieved.

Group I. Group I consisted of eight dogs with electromagnetic flowmeter probes and hydraulic occluders on the left circumflex coronary artery. Six of these dogs had electromagnetic flowmeter probes on the ascending aorta. During control conditions, the reactive hyperemia following a coronary artery occlusion of 5-s duration was observed. The reactive hyperemic response was then observed when a 5-s total coronary artery occlusion was performed and a sufficient volume of water subsequently withdrawn from the occluder to allow coronary flow to return to the preocclusion rate and held at this level for $20 \mathrm{~s}$. After this interval of restricted inflow, the occluder was completely released to allow the reactive hyperemic response. Studies were discarded if coronary flow during the interval of restricted inflow deviated from the preocclusion control rate by more than $5 \%$. The sequence in which occlusions were performed was randomized and each intervention was performed in duplicate.

After these control measurements, nitroglycerin, 0.015 $\mathrm{mg} / \mathrm{kg}$, dissolved in $3 \mathrm{ml}$ of normal saline was infused intravenously over a 60 -s interval. $5 \mathrm{~min}$ after beginning the infusion of nitroglycerin, the reactive hyperemic response to a 5-s total coronary occlusion followed by a 20 -s restriction of coronary inflow to the preocclusion rate of flow was again observed.

After a minimum of 90 min after administration of nitroglycerin, the reactive hyperemia following a 5-s simple coronary artery occlusion was again observed in duplicate. Subsequently, nitroglycerin, $0.015 \mathrm{mg} / \mathrm{kg}$, was again administered over a 60 -s interval by intravenous infusion. $5 \mathrm{~min}$ after administration of nitroglycerin, the reactive

\footnotetext{
${ }^{2}$ Model P23Db, Statham Laboratories, Inc., Hato-Rey, Puerto Rico.

${ }^{3}$ Hewlett-Packard Co., Waltham, Mass.
} 
hyperemic response to a simple 5-s coronary artery occlusion was again observed.

Studies were discarded in which heart rate, mean aortic flow, or aortic blood pressure differed by more than $5 \%$ from control values during the occlusion and to the end of the reactive hyperemic response. The volume of flow during reactive hyperemia was determined by electrical integration by a Hewlett-Packard model 8815-A analog computer. $^{3}$ The duration of reactive hyperemia was taken as the time required for flow to fall to within $5 \%$ of the control measurement. Mean coronary and aortic blood flow and aortic blood pressure were measured directly from the recordings. Calculations of blood flow debt incurred during arterial occlusion, reactive hyperemic flow, and blood flow debt repayments were made as described by Freeman (12) :

Blood flow debt (milliliter) = control flow rate (milliliter per second) $\times$ duration of occlusion (second) ;

Reactive hyperemic flow (milliliter) $=$ (total flow during reactive hyperemia [milliliter] $)-($ control flow rate [milliliter per second] $\times$ duration of reactive hyperemia [second ] ) ;

Blood flow debt repayment (percent $)=$ (reactive hyperemic flow/blood flow debt) $\times 100$.

Measurements of distribution of myocardial blood flow were made by injecting into the left atrium carbonized microspheres $7-10 \mu \mathrm{m}$ in diameter labeled with gamma-emitting radionuclides ${ }^{141} \mathrm{Ce},{ }^{51} \mathrm{Cr},{ }^{85} \mathrm{Sr}$, or ${ }^{46} \mathrm{Sc}^{4}{ }^{4}$ Microspheres were obtained as $1.0 \mathrm{mCi}$ of each nuclide in $10 \mathrm{ml}$ of $10 \%$ dextran and $0.5 \%$ polysorbate 80 . This stock solution was diluted in $10 \%$ dextran so that $1.0 \mathrm{ml}$ contained two million microspheres. Before injection, microspheres were mixed by alternate agitation for at least $15 \mathrm{~min}$ in an ultrasonic bath and a Vortex agitator (Scientific Industries, Inc., Queens Village, N. Y.). Complete dispersion of microspheres was verified by examining a drop of microsphere suspension with a light microscope before injection.

In each $\operatorname{dog} 1.5 \mathrm{ml}$ of suspension containing three million microspheres was injected into the left atrium during resting control conditions. This and all subsequent microsphere injections were made over a 5-s interval and the left atrial catheter was then flushed with $3 \mathrm{ml}$ of normal saline during the following 5-s interval. Beginning simultaneously with the microsphere injection and continuing for $90 \mathrm{~s}$, a reference sample of arterial blood was collected from the aortic catheter at a constant rate of $15 \mathrm{ml} / \mathrm{min}$ by using a withdrawal pump. ${ }^{5}$

To evaluate the distribution of myocardial blood flow when coronary vasodilation was produced by an ischemic stimulus, but coronary inflow prevented from increasing above the control level, a 5-s coronary artery occlusion was produced and the occluder then partially deflated to allow coronary flow to return to the preocclusion control rate of flow but to prevent any reactive hyperemia. Beginning $5 \mathrm{~s}$ after restoration of coronary artery inflow to the control rate, $1.5 \mathrm{ml}$ of microsphere suspension labeled with a second radionuclide was injected into the left atrium. Coronary artery flow was maintained at the preocclusion rate for an additional $40 \mathrm{~s}$ to insure complete dispersion of microspheres before the occluder was completely released.

Nitroglycerin, $0.015 \mathrm{mg} / \mathrm{kg}$, dissolved in $3 \mathrm{ml}$ of normal saline was then administered intravenously over a 60 -s interval. $5 \mathrm{~min}$ after beginning the nitroglycerin infusion, a 5 -s coronary artery occlusion was produced and the occluder then partially deflated to allow coronary flow to

\footnotetext{
${ }^{4} 3 \mathrm{M}$ Co., St. Paul, Minn.

${ }^{5}$ Model 1210, Harvard Apparatus Co., Inc., Millis, Mass.
}

return to the preocclusion control rate of flow, but to prevent any reactive hyperemia. Beginning $5 \mathrm{~s}$ after restoration of coronary inflow to the control rate, $1.5 \mathrm{ml}$ of microspherc suspension labeled with a third radionuclide was injected into the left atrium. As before, coronary artery flow was maintained at the preocclusion rate for an additional $40 \mathrm{~s}$ to insure complete dispersion of microspheres before the occluder was completely released.

After completion of the study, the animal was sacrificed with a lethal dose of pentobarbital and the heart removed and fixed in $10 \%$ buffered formalin. The atria, right ventricle, aorta, and large epicardial blood vessels were dissected from the left ventricle and discarded. The left ventricle was then sectioned into four transverse sections of approximately equal thickness parallel to the mitral valve ring as previously described (13). The two central sections which constituted $61 \pm 6 \%$ of the left ventricular weight were used for study. Two full-thickness tissue blocks, each encompassing approximately $1.5 \mathrm{~cm}$ of the outer circumference of each of the two central sections, were removed from the posterior left ventricular free wall and posterior papillary muscle region. Since injections of methylene blue into the circumflex coronary artery demonstrated uniform myocardial staining within a distribution encompassing these tissue blocks, these specimens were taken to represent the myocardial regions under study. Each tissue block was divided into equal outer (epicardial) and inner (endocardial) layers, weighed, and placed in vials for counting.

Radioactivity was determined with a gamma spectrometer $^{6}$ using window settings corresponding to the peak energies emitted by each radionuclide. The activities recorded in each energy window and the corresponding sample weights were then entered into a digital computer ${ }^{7}$ programmed to correct activity recorded in each window for contaminant activity contributed by the associated nuclide and for background activity and to compute the corrected counts per minute per gram of myocardium. From the rate of withdrawal of the reference sample $\left(Q_{r}\right)$ and the radioactivity $\left(C_{r}\right)$ in the reference sample, and since the ratio of flow to activity is uniform because complete mixing of microspheres with blood occurred during passage through the left ventricle, myocardial radioactivity $\left(C_{m}\right)$ was used to compute myocardial blood flow $\left(Q_{m}\right)$ as :

$$
Q_{m}=Q_{r} \cdot C_{m} / C_{r} \text {. }
$$

Group II. Group II consisted of six dogs with electromagnetic flowmeters on the left circumflex coronary artery and catheters in the ascending aorta and coronary sinus for determination of myocardial oxygen consumption. Three of these dogs were also included in group I. Coronary sinus catheterization was accomplished with a- no. 7 French Sones cardiac catheter introduced through the left external jugular vein by using $2 \%$ lidocaine infiltration anesthesia and positioned under fluoroscopic control. Placement of the catheter tip 1-2 cm past the bend of the coronary sinus was confirmed by observing its position while the coronary sinus was opacified by injecting $3-4 \mathrm{ml}$ of $75 \%$ sodium diatriazoate at the beginning and end of each study. This catheter position has been demonstrated to yield venous blood uncontaminated by right atrial blood (14).

During resting control conditions myocardial arteriovenous oxygen difference was estimated by using duplicate

${ }^{6}$ Model 167776, Beckman Instruments, Inc., Fullerton, Calif.

${ }^{7}$ Model 1130, International Business Machines Corp., Armonk, N. Y. 
TABLE I Hemodynamic Data (Group I)

\begin{tabular}{lccccc}
\hline & $\begin{array}{c}\text { Heart } \\
\text { rate }\end{array}$ & $\begin{array}{c}\text { Aortic } \\
\text { pressure }\end{array}$ & $\begin{array}{c}\text { Atrial } \\
\text { pressure }\end{array}$ & $\begin{array}{c}\text { Aortic } \\
\text { flow }\end{array}$ & $\begin{array}{c}\text { Coronary } \\
\text { flow }\end{array}$ \\
\hline \multirow{4}{*}{ Control } & beats/min & \multicolumn{2}{c}{$\mathrm{mm} \mathrm{Hg}$} & \multicolumn{2}{c}{$\mathrm{ml} / \mathrm{min}$} \\
& 81 & 94 & 6.4 & 2,550 & 32.6 \\
Nitroglycerin & \pm 5 & \pm 3 & \pm 1.3 & \pm 270 & \pm 2.6 \\
& 84 & 91 & 5.4 & 2,350 & 34.2 \\
$P$ & \pm 8 & \pm 3 & \pm 1.3 & \pm 260 & \pm 4.0 \\
& $\mathrm{NS}$ & $\mathrm{NS}$ & $<0.05$ & $<0.05$ & $\mathrm{NS}$ \\
\hline
\end{tabular}

Heart rate, aortic and left atrial blood pressures, ascending aortic blood flow, and flow through the left circumflex coronary artery during resting control conditions and $5 \mathrm{~min}$ after administration of nitroglycerin, 0.015 $\mathrm{mg} / \mathrm{kg}$, by intravenous infusion over a 60 -s interval to dogs in group I. Values are mean \pm SEM.

blood specimens drawn simultaneously from the aortic and coronary sinus catheters. Myocardial oxygen consumption wis computed as the product of flow measured in the left circumflex coronary artery and myocardial arteriovenous oxygen difference. Nitroglycerin, $0.015 \mathrm{mg} / \mathrm{kg}$, dissolved in $3 \mathrm{ml}$ of normal saline was then infused intravenously over a 60 -s interval. $5 \mathrm{~min}$ after beginning the nitroglycerin infusion, duplicate blood specimens were again obtained from the aortic and coronary sinus catheters. Hemodynamic measurements were recorded continuously throughout the course of the study.

Hemoglobin content and oxygen saturation of each blood specimen were determined in duplicate by using an oximeter ${ }^{8}$ previously calibrated with the Van Slyke manometric apparatus. This oximeter was capable of duplicating oxygen saturation measured with the Van Slyke apparatus within $95 \%$ confidence limits of $\pm 3.6 \%$.

Group III. Group III consisted of six dogs with only a hydraulic occluder on the left circumflex coronary artery and indwelling catheters in the ascending aorta and left atrium. These animals were used to study the effects of nitroglycerin upon transmural myocardial blood flow during resting control conditions, as well as to assess the effect of nitroglycerin upon collateral inflow distal to an acute coronary artery occlusion.

While the animals were resting quietly, three million radionuclide-labeled microspheres dissolved in $1.5 \mathrm{ml}$ of $10 \%$ dextran were injected into the left atrium while a reference specimen of arterial blood was collected from the aortic catheter as previously described. Subsequently, nitroglycerin, $0.015 \mathrm{mg} / \mathrm{kg}$, was administered intravenously over a 60 -s interval. $5 \mathrm{~min}$ after beginning the nitroglycerin infusion, a second dosage of three million microspheres labeled with a different radionuclide was injected into the left atrium.

A minimum of $90 \mathrm{~min}$ was allowed for dissipation of the effects of nitroglycerin before the subsequent intervention was performed. The left circumflex coronary artery was occluded by injecting $1.0 \mathrm{ml}$ of water into the occluder tubing. Beginning $5 \mathrm{~s}$ after application of the coronary occlusion, three million microspheres labeled with a third radionuclide were injected into the left atrium as previously described. The coronary occlusion was maintained for a total interval of $60 \mathrm{~s}$ to insure complete dispersion of microspheres in the arterial circulation before release of occlusion. $10 \mathrm{~min}$ after this intervention, nitroglycerin, $0.015 \mathrm{mg} / \mathrm{kg}$,

${ }^{8}$ Model 182, Instrumentation Laboratory, Inc., Lexington, Mass. was again administered intravenously over a 60 -s interval. 5 min after beginning the nitroglycerin infusion, a coronary artery occlusion was performed, and $5 \mathrm{~s}$ after the onset of occlusion, three million microspheres labeled with the fourth radionuclide were injected into the left atrium. The occlusion was again maintained for a total duration of $60 \mathrm{~s}$. In three of the six animals the sequence of study was reversed so that the distribution of microspheres during coronary artery occlusion was studied first, while the control distribution of microspheres was studied second. The dogs were sacrificed, the hearts sectioned, and myocardial blood flow determined as previously described.

Data analysis using Student's $t$ test for paired data was performed with a digital computer.

\section{RESULTS}

Group I. Mean heart rate, aortic and left atrial blood pressures, and aortic and coronary blood flows measured in eight dogs in group I are shown in Table I. 5 min after administration of nitroglycerin, heart rate, aortic pressure, and coronary blood flow were not significantly different from the pretreatment control values, while left atrial pressure and mean aortic flow were slightly but significantly below the control values.

Fig. 1 illustrates the left circumflex coronary artery reactive hyperemic responses observed in a typical dog. Table II summarizes the reactive hyperemia data from eight dogs. During control conditions a 5-s coronary artery occlusion resulted in a blood flow debt of $2.71 \pm$ $0.40 \mathrm{ml}$. Release of occlusion resulted in a reactive hyperemia $30 \pm 3 \mathrm{~s}$ in duration during which excess arterial inflow of $9.78 \pm 1.20 \mathrm{ml}$ resulted in $360 \pm 15 \%$ blood flow debt repayment. The duration of reactive hyperemia and blood flow debt repayment observed 5 min after administration of nitroglycerin was not significantly different from the control response (Table IIA).

When, after a 5-s coronary artery occlusion, the occluder was partially deflated to allow coronary artery inflow to return to the preocclusion rate and held at this level for $20 \mathrm{~s}$, complete release of the occlusion was followed by an augmented reactive hyperemic response $62 \pm 8 \mathrm{~s}$ in duration during which $21.1 \pm 3.85 \mathrm{ml}$ of excess arterial inflow occurred, resulting in $775 \pm 105 \%$ blood flow debt repayment (Fig. 1, Table IIB). The volume of excess arterial inflow during this response was significantly greater than that observed after a control 5-s coronary artery occlusion $(P<0.01) .5$ min after administration of nitroglycerin, when a 5-s coronary artery occlusion was followed by restriction of arterial inflow to the preocclusion control level for $20 \mathrm{~s}$, complete release of the occlusion resulted in a reactive hyperemic response $47 \pm 7 \mathrm{~s}$ in duration during which $12.0 \pm$ $1.47 \mathrm{ml}$ of excess arterial inflow occurred, resulting in $420 \pm 55 \%$ blood flow debt repayment. This response following nitroglycerin was significantly less than the reactive hyperemia following an identical 5-s occlusion with subsequent $20-\mathrm{s}$ restriction of arterial inflow to 


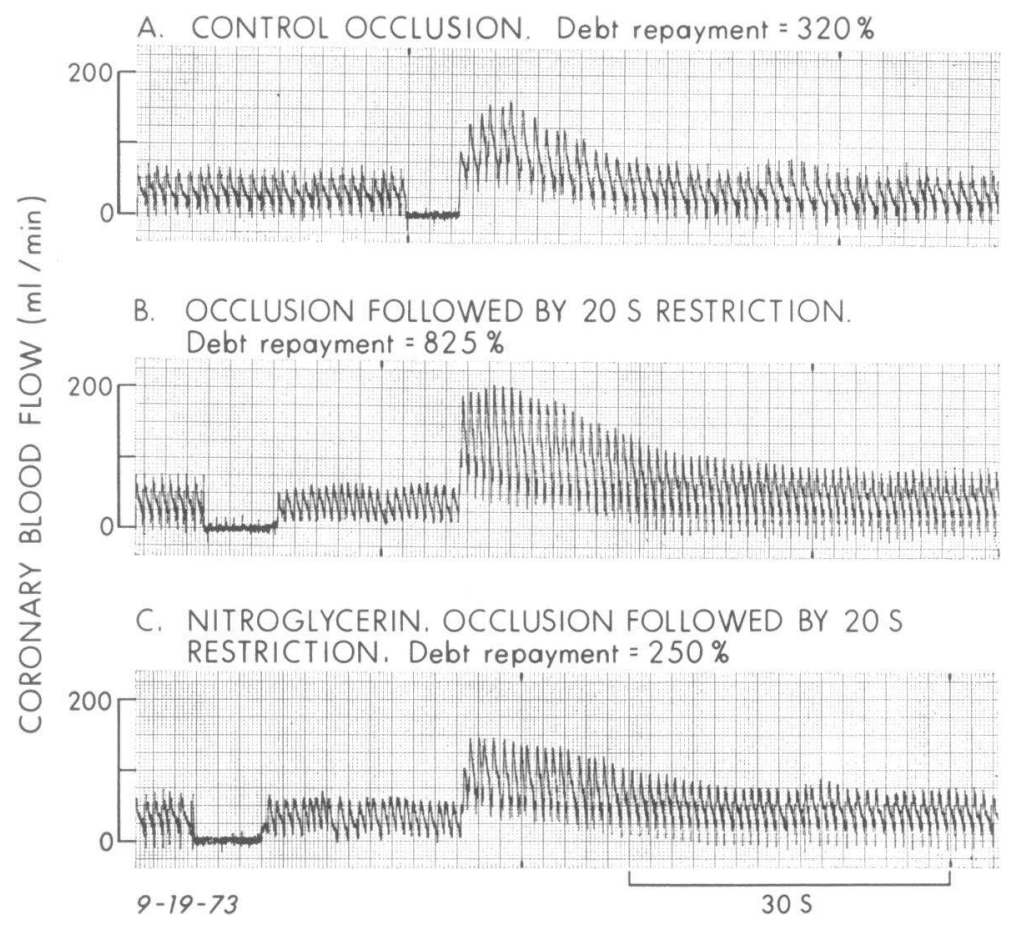

Figure 1 Left circumflex coronary blood flow in a 25-kg awake dog. (A) After a 5-s coronary artery occlusion, reactive hyperemia resulted in $320 \%$ blood flow debt repayment. (B) When a 5-s occlusion was followed by a 20 -s interval during which coronary artery inflow was restricted to the preocclusion control level, complete release of the occluder resulted in a significantly augmented reactive hyperemic response with $825 \%$ blood flow debt repayment. (C) $5 \mathrm{~min}$ after nitroglycerin, $0.015 \mathrm{mg} / \mathrm{kg}$, a 5 -s occlusion followed by a 20 -s interval during which coronary inflow was restricted to the preocclusion control level resulted in reactive hyperemia with $250 \%$ blood flow debt repayment.

the control level before administration of nitroglycerin $(P<0.01)$ and was not significantly different from the reactive hyperemia which followed a simple 5-s coronary artery occlusion.

Regional myocardial blood flow to the left ventricular posterior free wall and posterior papillary muscle region is shown in Table III. During resting control conditions epicardial flow ranged from 0.63 to $0.76 \mathrm{ml} /$ min per $g$ of myocardium, while endocardial flow ranged from 0.82 to $0.87 \mathrm{ml} / \mathrm{min}$ per $\mathrm{g}$ of myocardium. Endocardial flow was significantly greater than epicardial flow in ring $2(P<0.02)$, but not in ring 3 . Thus, the ratio of endocardial to epicardial flow in ring 2 during control conditions was significantly greater than unity (Fig. 2).

When arterial inflow was restricted to the control rate during coronary vasodilation induced by a 5 -s coronary occlusion, mean epicardial flow in the posterior free wall and posterior papillary muscle region was increased $19 \pm 5 \%$ above the control value $(P<0.01)$ (Table III). In contrast to this, mean endocardial flow within these posterior regions was decreased $24 \pm 6 \%$ below the control level $(P<0.01)$. Consequently, the ratio of endocardial to epicardial flow was significantly decreased below the control level and below unity in the regions under study (Fig. 2) $(P<0.01)$ In contrast to this, $5 \mathrm{~min}$ after nitroglycerin administration, no redistribution of myocardial blood flow occurred when coronary inflow was restricted to the preocclusion rate after a 5-s coronary artery occlusion, so that regional myocardial blood flow during this interval was not significantly different from the resting control situation (Table III). The ratio of endocardial to epicardial flow after nitroglycerin was not significantly different from that observed during the control situation (Fig. 2).

Group II. In six dogs in which myocardial oxygen consumption was measured, mean coronary blood flow during resting control conditions was $27.8 \pm 2.5 \mathrm{ml} / \mathrm{min}$ with a mean coronary arteriovenous oxygen difference of $11.93 \pm 0.45 \mathrm{ml} / 100 \mathrm{ml}$ of blood, yielding a myocardial oxygen consumption of $3.28 \pm 0.21 \mathrm{ml} / \mathrm{min}$ (Table IV). When these measurements were repeated $5 \mathrm{~min}$ after intravenous administration of nitroglycerin, resting coronary blood flow was $27.1 \pm 1.7 \mathrm{ml} / \mathrm{min}$, while arteriovenous oxygen difference was $12.56 \pm 0.64 \mathrm{ml} / 100 \mathrm{ml}$ of blood, yielding a mean myocardial oxygen consump- 
TABLE II

Reactice Hyperemia Data (Group I)

\begin{tabular}{|c|c|c|c|c|c|c|c|c|c|c|c|c|}
\hline \multirow[b]{3}{*}{ Dog } & \multicolumn{6}{|c|}{ A. Reactive hyperemia following 5-s coronary occlusion } & \multicolumn{6}{|c|}{$\begin{array}{l}\text { B. Reactive hyperemia following } 5-\mathrm{s} \text { occlusion with inflow } \\
\text { restricted to the preocclusion control value for } 20 \mathrm{~s}\end{array}$} \\
\hline & \multicolumn{2}{|c|}{$\begin{array}{l}\text { Coronary } \\
\text { blood flow }\end{array}$} & \multicolumn{2}{|c|}{$\begin{array}{l}\text { Reactive } \\
\text { hyperemia } \\
\text { duration }\end{array}$} & \multicolumn{2}{|c|}{$\begin{array}{c}\text { Blood flow } \\
\text { debt repayment }\end{array}$} & \multicolumn{2}{|c|}{$\begin{array}{l}\text { Coronary blood } \\
\text { flow during } \\
20-\text { s restriction }\end{array}$} & \multicolumn{2}{|c|}{$\begin{array}{l}\text { Reactive } \\
\text { hyperemia } \\
\text { duration }\end{array}$} & \multicolumn{2}{|c|}{$\begin{array}{c}\text { Blood flow } \\
\text { debt repayment }\end{array}$} \\
\hline & Con & TNG & Con & T.NG & Con & TNG & Con & TNG & Con & TNG & Con & TNG \\
\hline & \multicolumn{2}{|c|}{$\mathrm{ml} / \mathrm{min}$} & \multicolumn{2}{|c|}{$s$} & \multicolumn{2}{|c|}{$\%$} & \multicolumn{2}{|c|}{$\mathrm{ml} / \mathrm{min}$} & \multicolumn{2}{|c|}{$s$} & \multicolumn{2}{|c|}{$\%$} \\
\hline 1 & 27.0 & 31.5 & 23 & - & 295 & - & 26.5 & 30.2 & 72 & 31 & 475 & 220 \\
\hline 2 & 29.5 & 28.2 & 30 & - & 410 & - & 29.2 & 26.8 & 57 & 50 & 640 & 505 \\
\hline 3 & 40.0 & 42.5 & 41 & 36 & 410 & 420 & 40.8 & 42.9 & 87 & 66 & 1,240 & 420 \\
\hline 4 & 24.0 & 23.5 & 42 & 44 & 420 & 385 & 24.0 & 24.0 & 78 & 52 & 825 & 250 \\
\hline 5 & 31.0 & 26.5 & 20 & 15 & 360 & 350 & 30.4 & 26.5 & 20 & 35 & 520 & 370 \\
\hline 6 & 37.0 & 28.5 & 33 & 30 & 345 & 330 & 37.0 & 29.4 & 51 & 65 & 630 & 405 \\
\hline 7 & 44.0 & 56.0 & 24 & 37 & 395 & 450 & 44.4 & 56.0 & 54 & 36 & 755 & 485 \\
\hline 8 & 28.5 & 36.5 & 29 & 44 & 350 & 325 & 28.5 & 36.9 & 74 & 49 & 1,130 & 695 \\
\hline Mean & 32.6 & 34.2 & 30 & 34 & 360 & 375 & 32.6 & 34.1 & 62 & 47 & 775 & +20 \\
\hline SEM & \pm 2.6 & \pm 4.0 & \pm 3 & \pm 3 & \pm 15 & \pm 20 & \pm 2.8 & \pm 4.1 & \pm 8 & \pm 7 & \pm 105 & \pm 55 \\
\hline $\begin{array}{l}P(\text { Con } \\
\quad \text { vs. TNG })\end{array}$ & \multicolumn{2}{|c|}{ NS } & \multicolumn{2}{|c|}{ NS } & \multicolumn{2}{|c|}{ NS } & \multicolumn{2}{|c|}{ NS } & \multicolumn{2}{|c|}{ NS } & \multicolumn{2}{|c|}{$<0.01$} \\
\hline
\end{tabular}

Control left circumflex coronary artery blood flow, coronary flow during the 20-s interval of restricted inflow, and the reactive hyperemic responses in eight dogs in group I. The duration and blood flow debt repayment observed after control 5-s coronary artery occlusions (A) and after 5-s coronary artery occlusions with restriction of subsequent coronary flow to the preocclusion rate for $20 \mathrm{~s}$ (B) are shown during control conditions (Con) and $5 \mathrm{~min}$ after administration of nitroglycerin, $0.015 \mathrm{mg} / \mathrm{kg}$ (TNG).

TABLE III

Myocardial Blood Flow Data (Group I)

\begin{tabular}{|c|c|c|c|c|c|c|c|}
\hline \multirow[b]{2}{*}{ Ring } & \multirow[b]{2}{*}{ Layer } & \multicolumn{3}{|c|}{ Posterior left ventricular free wall flow } & \multicolumn{3}{|c|}{ Posterior papillary muscle region flow } \\
\hline & & Con & IIV & TNG & Con & IIV & TNG \\
\hline & & \multicolumn{3}{|c|}{$\mathrm{ml} / \mathrm{min}$ per $\mathrm{g}$} & \multicolumn{3}{|c|}{ ml/min per $\mathrm{g}$} \\
\hline \multirow[t]{5}{*}{2} & Epi & 0.63 & $0.79^{*}$ & $0.64_{\ddagger}^{+}$ & 0.73 & $0.87^{*}$ & 0.77 \\
\hline & & \pm 0.02 & \pm 0.03 & \pm 0.05 & \pm 0.03 & \pm 0.03 & \pm 0.07 \\
\hline & Endo & 0.87 & 0.74 & $0.82 \ddagger$ & 0.87 & $0.61^{*}$ & $0.85 \ddagger$ \\
\hline & & \pm 0.05 & \pm 0.03 & \pm 0.07 & \pm 0.04 & \pm 0.05 & \pm 0.08 \\
\hline & $P$ & $<0.02$ & NS & NS & $<0.01$ & $<0.03$ & NS \\
\hline \multirow[t]{5}{*}{3} & Epi & 0.74 & $0.86^{*}$ & 0.78 & 0.76 & $0.83^{*}$ & 0.73 \\
\hline & & \pm 0.06 & \pm 0.03 & \pm 0.08 & \pm 0.03 & \pm 0.03 & \pm 0.10 \\
\hline & Endo & 0.82 & $0.67^{*}$ & 0.76 & 0.86 & $0.53^{*}$ & $0.74+$ \\
\hline & & \pm 0.10 & \pm 0.05 & \pm 0.05 & \pm 0.04 & \pm 0.05 & \pm 0.09 \\
\hline & $P$ & NS & $<0.03$ & NS & NS & $<0.01$ & NS \\
\hline
\end{tabular}

Subepicardial (epi) and subendocardial (endo) myocardial blood flow in the left ventricular posterior free wall and posterior papillary muscle regions of eight dogs in group I. Myocardial blood flow measurements were obtained during control conditions (Con), during the interval of ischemia-induced coronary vasodilation following a 5-s occlusion of the left circumflex coronary artery while arterial inflow was held to the preocclusion control rate (IIV), and 5 min after administration of nitroglycerin, $0.015 \mathrm{mg} / \mathrm{kg}$, while coronary artery inflow was held to the preocclusion control rate after a 5-s coronary artery occlusion (TNG). Values are mean $\pm \mathrm{SEM}$. ${ }^{*} P<0.05$ in comparison with the corresponding flow measured during control conditions. $\ddagger P<0.05$ between IIV and TNG.

1224 Bache, Ball, Cobb, Rembert, and Greenfield 
tion of $3.39 \pm 0.23 \mathrm{ml} / \mathrm{min}$. None of these values were significanlty altered after administration of nitroglycerine.

Group III. Regional myocardial blood flow in the left ventricular posterior free wall and posterior papillary muscle region for six dogs in group III are shown in Table $\mathrm{V}$. During resting control conditions regional myocardial blood flow $5 \mathrm{~min}$ after administration of nitroglycerin, $0.015 \mathrm{mg} / \mathrm{kg}$, was not different from the pretreatment control value. During occlusion of the left circumflex coronary artery, mean subepicardial blood flow fell to $17 \pm 3 \%$ of the control value while mean subendocardial flow fell to $14 \pm 2 \%$ of the control value. After administration of nitroglycerin, acute occlusion of the circumflex coronary artery resulted in statistically similar decreases of myocardial blood flow, subepicardial flow falling to $20 \pm 2 \%$ of the preocclusion value while subendocardial flow fell to $17 \pm 2 \%$ of the preocclusion control value. Thus, nitroglycerin did not significantly alter coronary collateral inflow distal to an acute coronary artery occlusion.

\section{DISCUSSION}

In the coronary circulation the reactive hyperemic response is closely coupled to myocardial metabolic activity so that alterations of myocardial oxygen consumption or alterations of the duration of arterial occlusion are accompanied by commensurate alterations of the reactive hyperemia to maintain a nearly constant blood flow debt repayment (15-17). Because of this quantitative relationship between moycardial ischemia and the subsequent reactive hyperemia, it is reasonable that the magnitude of the reactive hyperemic response could be used to evaluate the degree of preceding ischemia. Consequently, the finding that reactive hyperemia fol-

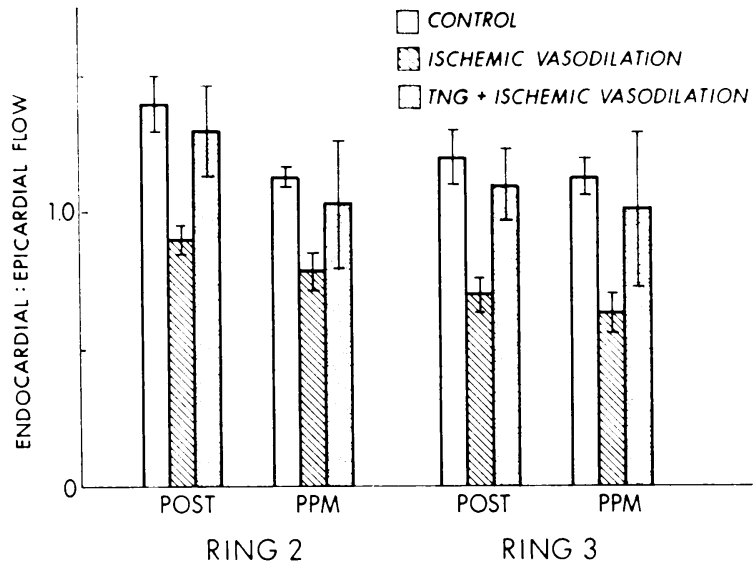

FigLre 2 The ratio of endocardial to epicardial flow in the left ventricular posterior free wall (POST) and posterior papillary muscle region (PPM) in 11 awake dogs. Studies were performed during control conditions, during an interval of ischemia-induced vasodilation when a 5-s coronary artery occlusion was followed by restriction of arterial inflow to the preocclusion control rate, and $5 \mathrm{~min}$ after administration of nitroglycerin, $0.015 \mathrm{mg} / \mathrm{kg}$, during a similar interval of ischemia-induced vasodilation when a 5-s coronary occlusion was followed by restriction of arterial inflow to the preocclusion control rate. Values are mean \pm SEM.

lowing a 5-s coronary occlusion was augmented by imposing a 20 -s interval during which arterial inflow was restricted to the preocclusion control level before complete release of the occluder suggested that ischemia was continuing during the interval of restricted inflow. Since the rate of arterial inflow during this interval had been sufficient to maintain myocardial metabolic activity before occlusion, it is necessary to explain why this same volume of arterial blood was not adequate to

TABLE IV

Myocardial Oxygen Consumption Data (Group II)

\begin{tabular}{|c|c|c|c|c|c|c|c|c|c|c|}
\hline \multirow[b]{2}{*}{ Dog } & \multicolumn{2}{|c|}{$\begin{array}{l}\text { Coronary } \\
\text { blood flow }\end{array}$} & \multicolumn{2}{|c|}{$\begin{array}{c}\text { Arterial } \\
\text { oxygen content }\end{array}$} & \multicolumn{2}{|c|}{$\begin{array}{l}\text { Coronary sinus } \\
\text { oxygen content }\end{array}$} & \multicolumn{2}{|c|}{$\begin{array}{c}\text { Arteriovenous } \\
\text { oxygen difference }\end{array}$} & \multicolumn{2}{|c|}{$\begin{array}{l}\text { Myocardial oxygen } \\
\text { consumption }\end{array}$} \\
\hline & Con & TNG & Con & T.YG & Con & $\mathrm{TNG}$ & Con & TNG & Con & TNG \\
\hline & \multicolumn{2}{|c|}{$\mathrm{ml} / \mathrm{min}$} & \multicolumn{6}{|c|}{$\mathrm{ml} / 100 \mathrm{ml}$} & \multicolumn{2}{|c|}{$\mathrm{ml} / \mathrm{min}$} \\
\hline 1 & 25.5 & 23.5 & 16.31 & 16.33 & 4.90 & 4.16 & 11.41 & 13.17 & 2.91 & 2.86 \\
\hline 2 & 25.0 & 24.5 & 15.83 & 15.83 & 4.16 & 4.92 & 11.67 & 10.97 & 2.92 & 2.69 \\
\hline 3 & 31.5 & 31.0 & 16.21 & 16.24 & 4.84 & 4.73 & 11.37 & 11.51 & 3.58 & 3.57 \\
\hline 4 & 21.5 & 22.0 & 17.81 & 18.08 & 4.57 & 3.06 & 13.24 & 15.02 & 2.85 & 3.45 \\
\hline 5 & 37.0 & 31.0 & 16.41 & 16.63 & 5.62 & 4.05 & 10.79 & 12.58 & 3.99 & 3.90 \\
\hline 6 & 26.0 & 29.5 & 15.58 & 15.72 & 2.46 & 2.60 & 13.12 & 13.12 & 3.41 & 3.87 \\
\hline Mean & 27.8 & 27.1 & 16.36 & 16.47 & 4.43 & 3.92 & 11.93 & 12.56 & 3.28 & 3.39 \\
\hline SEM & \pm 2.5 & \pm 1.7 & \pm 0.35 & \pm 0.38 & \pm 0.48 & \pm 0.41 & \pm 0.45 & \pm 0.64 & \pm 0.21 & \pm 0.23 \\
\hline
\end{tabular}

Left circumflex coronary artery blood flow, arterial and coronary sinus oxygen content, myocardial arteriovenous oxygen difference, and myocardial oxygen consumption in six awake dogs during resting control conditions (Con) and 5 min after administration of nitroglycerin, $0.015 \mathrm{mg} / \mathrm{kg}$, by intravenous infusion over a 60 -s interval (TNG). 
TABLE V

Myocardial Blood Flow Data (Group III)

\begin{tabular}{|c|c|c|c|c|c|c|c|c|c|c|c|c|c|}
\hline \multirow[b]{3}{*}{ Ring } & \multirow[b]{3}{*}{ Layer } & \multicolumn{6}{|c|}{ Posterior left ventricular free wall flow } & \multicolumn{6}{|c|}{ Posterior papillary muscle region flow } \\
\hline & & \multicolumn{3}{|c|}{ No occlusion } & \multicolumn{3}{|c|}{ Occlusion } & \multicolumn{3}{|c|}{ No occlusion } & \multicolumn{3}{|c|}{ Occlusion } \\
\hline & & Con & TNG & $P$ & Con & TNG & $P$ & Con & TNG & $P$ & Con & TNG & $P$ \\
\hline & & \multicolumn{3}{|c|}{$m l / m i n$ per $g$} & \multicolumn{3}{|c|}{$m l / m i n$ per $g$} & \multicolumn{3}{|c|}{$\mathrm{ml} / \mathrm{min}$ per $\mathrm{g}$} & \multicolumn{3}{|c|}{$\mathrm{ml} / \mathrm{min}$ per $\mathrm{g}$} \\
\hline 2 & Epi & $\begin{array}{r}0.68 \\
\pm 0.05\end{array}$ & $\begin{array}{r}0.67 \\
\pm 0.06\end{array}$ & $>0.7$ & $\begin{array}{r}0.15 \\
\pm 0.05\end{array}$ & $\begin{array}{r}0.19 \\
\pm 0.08\end{array}$ & $>0.1$ & $\begin{array}{r}0.79 \\
\pm 0.08\end{array}$ & $\begin{array}{r}0.81 \\
\pm 0.09\end{array}$ & $>0.7$ & $\begin{array}{r}0.07 \\
\pm 0.02\end{array}$ & $\begin{array}{r}0.10 \\
\pm 0.02\end{array}$ & $>0.1$ \\
\hline & Endo & $\begin{array}{r}0.85 \\
\pm 0.07\end{array}$ & $\begin{array}{r}0.87 \\
\pm 0.08\end{array}$ & $>0.5$ & $\begin{array}{r}0.13 \\
\pm 0.08\end{array}$ & $\begin{array}{r}0.18 \\
\pm 0.08\end{array}$ & $>0.06$ & $\begin{array}{r}0.84 \\
\pm 0.07\end{array}$ & $\begin{array}{r}0.88 \\
\pm 0.11\end{array}$ & $>0.7$ & $\begin{array}{r}0.02 \\
\pm 0.01\end{array}$ & $\begin{array}{r}x 0.02 \\
0.05 \\
\pm 0.01\end{array}$ & $>0.1$ \\
\hline 3 & Epi & $\begin{array}{r}0.69 \\
\pm 0.05\end{array}$ & $\begin{array}{r}0.70 \\
\pm 0.08\end{array}$ & $>0.8$ & $\begin{array}{r}0.17 \\
\pm 0.08\end{array}$ & $\begin{array}{r}0.21 \\
\pm 0.07\end{array}$ & $>0.6$ & $\begin{array}{r}0.81 \\
\pm 0.08\end{array}$ & $\begin{array}{r}0.83 \\
\pm 0.10\end{array}$ & $>0.6$ & $\begin{array}{r}0.10 \\
\pm 0.02\end{array}$ & $\begin{array}{r}0.10 \\
\pm 0.01\end{array}$ & $>0.8$ \\
\hline & Endo & $\begin{array}{r}0.85 \\
\pm 0.08\end{array}$ & $\begin{array}{r}0.85 \\
\pm 0.09\end{array}$ & $>0.9$ & $\begin{array}{r}0.25 \\
\pm 0.11\end{array}$ & $\begin{array}{r}0.27 \\
\pm 0.10\end{array}$ & $>0.5$ & $\begin{array}{r}0.81 \\
\pm 0.06\end{array}$ & $\begin{array}{r}0.90 \\
\pm 0.11\end{array}$ & $>0.6$ & $\begin{array}{r}x 0.02 \\
0.06 \\
\pm 0.03\end{array}$ & $\begin{array}{r}0.09 \\
\pm 0.04\end{array}$ & $>0.2$ \\
\hline
\end{tabular}

Subepicardial (epi) and subendocardial (endo) myocardial blood flow in the left ventricular posterior free wall and posterior papillary muscle regions of six awake dogs in group III. Myocardial blood flow measurements were obtained during control conditions (Con) and 5 min after administration of nitroglycerin, $0.015 \mathrm{mg} / \mathrm{kg}$ (TNG), with unrestricted coronary inflow and during acute total occlusion of the left circumflex coronary artery. Values are mean \pm SEM.

prevent an increasing blood flow debt after the 5-s total occlusion.

Because cardiac contraction impedes blood flow into the subendocardium during systole, uniform transmural perfusion is dependent upon a gradient of blood flow favoring the subendocardium during diastole (2). During normal conditions it appears that sufficient vasodilator capacity resides at the subendocardial resistance vessels to maintain this compensatory gradient of favoring perfusion of the subendocardium. Myocardial ischemia may, by causing generalized coronary vasodilation, limit the ability of the subendocardial vessels to maintain diastolic resistance sufficiently low to sustain the necessary transmural gradient of flow to compensate for lack of systolic perfusion (3-5). Thus, in the present study, vasodilation resulting from a 5 -s occlusion impaired the ability of the coronary vasculature to maintain a uniform transmural distribution of myocardial blood flow during the interval of restricted inflow. As a consequence, flow to the subepicardium was increased and flow to the subendocardium was decreased while the total volume of arterial inflow remained unchanged. As expected, the final result of ischemia continuing within the subendocardium was an increase in the reactive hyperemic response when the occlusion was finally completely released.

Measurements of regional myocardial blood flow confirmed the proposed redistribution of flow during the interval when coronary inflow was restricted to the preocclusion control level after a 5-s coronary occlusion. During this interval, the epicardial layer received more blood than during control conditions while How to the subendocardial layer was reduced below the control level. Both the augmentation of the reactive hyperemia following restricted arterial inflow and the mal- distribution of transmural blood flow were corrected by pretreatment with nitroglycerin. The mechanism by which nitroglycerin reversed this phenomenon was the subject of further study. Nitroglycerin did not exert its action by a direct effect on the reactive hyperemic response, since reactive hyperemia following a simple 5 -s coronary artery occlusion was not altered by pretreatment with nitroglycerin. This confirms similar previous findings in the open-chest dog by Winbury, Howe, and Hefner (7).

The effect of nitroglycerin on abolishing augmentation of reactive hyperemia following a 20 -s interval of restricted inflow might have resulted from vasodilation by nitroglycerin of preexisting intercoronary collateral channels. The resulting increased collateral inflow during the period of occlusion and subsequent arterial restriction could have facilitated partial recovery of coronary vascular tone before complete release of the occluder. In previous studies using open-chest dogs, Fam and McGregor (18) found that nitroglycerin resulted in no increase in retrograde flow from the left circumflex coronary artery distal to an acute arterial occlusion of normal dogs, although nitroglycerin did increase retrograde flow in dogs in which growth of collateral vasculature had been stimulated by production of chronic myocardial ischemia. In the present study, nitroglycerin resulted in no significant increase in collateral inflow distal to an acute coronary artery occlusion. Thus, the effect of nitroglycerin on reactive hyperemia following restricted arterial inflow did not appear to occur from any effect on innate, preexisting intercoronary collateral channels.

A third mechanism by which nitroglycerin could have exerted its effect would have been by reduction of myocardial oxygen consumption without a concomitant re- 
duction of coronary blood flow. The net result of such an effect would be decreased myocardial oxygen extraction with increased oxygen content of coronary venous blood. In this situation, during the interval when coronary flow was restricted to the preocclusion control level considerable capacity to increase oxygen extraction would exist and the blood flow debt might, at least in part, have been repaid by increasing oxygen extraction without need for further increase of coronary blood flow. In man, nitroglycerin has been demonstrated to decrease left ventricular volume secondary to reduction of arterial pressure as well as to decreased venous return resulting from systemic venodilation $(10,20)$. Reduction of left ventricular volume would result in decreased left ventricular systolic tension development, a major determinant of myocardial oxygen consumption (21). In the present study, however, measurements 5 min after administration of nitroglycerin demonstrated no change in mean arterial pressure and only a modest decrease in mean left atrial pressure, with no change in myocardial oxygen consumption, myocardial arteriovenous oxygen extraction, or coronary venous oxygen content. The lack of effect of nitroglycerin on myocardial oxygen consumption in the present study may have resulted from $(a)$ the supine position of the animals, which would decrease the possibility of venous pooling and resultant decreased venous return and $(b)$ the presence of normal cardiovascular dynamics in these experimental animals. In patients with left ventricular decompensation, both arterial and venous tone may be increased above normal, and nitroglycerin might be expected to be effective in reducing these values and consequently reducing left ventricular volume and myocardial oxygen consumption (22).

A fourth potential mechanism by which nitroglycerin might act was proposed by Winbury, Howe, and Weiss (23). These workers postulated that nitroglycerin increases the open capillary density in the subepicardial myocardium to allow adequate tissue oxygenation at lower subepicardial blood flow rates, thereby making additional blood available to the subendocardium. However, recent studies of the small vessel blood content of the left ventricular myocardium by Weiss and Winbury (24) failed to demonstrate a significant effect of nitroglycerin upon transmural blood volume and led these workers to conclude that nitroglycerin does not significantly alter the transmural open capillary density.

It is possible that the action of nitroglycerin may be related to the differing effects which ischemia and nitroglycerin have on the coronary vascular system. While diastolic flow into the subepicardium is principally controlled by the resistance at the precapillary level, flow to the subendocardial myocardium is additionally influenced by the resistance of the penetrating arterial vessels which conduct blood from the epicardial surface across the wall of the left ventricle. Consequently, adequate subendocardial perfusion is dependent upon the ability of the subendocardial precapillary vessels to maintain sufficiently low resistance relative to the subepicardial vessels during diastole to compensate for both lack of systolic perfusion and for the additional series resistance offered by the transmural vessels which conduct blood across the left ventricular wall.

During normal conditions the resistance of the penetrating arteries appears to be low in relation to the precapillary resistance, so that vasodilation at the subendocardial precapillary level can readily compensate for this added series resistance and maintain net subendocardial perfusion equal to or slightly greater than subepicardial perfusion (2). If generalized vasodilation of the precapillary vessels occurred, however, it is possible that their ability to compensate for the resistance of the penetrating arteries would be impaired. In this situation the resistance of the penetrating vessels could assume major importance in determining whether the limited arterial inflow is delivered principally into the most proximal subepicardial channels at the expense of underperfusion of the more distal subendocardial channels. Myocardial ischemia results in vasodilation of the precapillary resistance vessels but not of the larger epicardial conductance vessels $(7,25)$. When resistance at the level of precapillary vessels becomes low, the effect of the resistance of the penetrating vessels which separate subepicardial from subendocardial precapillary vessels obviously becomes relatively more important. Although direct measurement of the vascular resistance at the level of the transmural penetrating arteries is not possible, Winbury et al. $(7,23,26)$ have provided data suggesting that these vessels behave similarly to epicardial arteries and are not dilated by ischemia. In contrast to the effects of ischemia, nitroglycerin results in only transient vasodilation of the precapillary vessels of 1-2-min duration, but causes prolonged vasodilation of the larger coronary conductance vessels $(6,7,25-27)$. If nitroglycerin effects vasodilation of the penetrating arteries not produced by ischemia, the resultant lowered resistance of these channels would be expected to facilitate delivery of blood to the subendocardium. This proposed mechanism could thus account for the observed correction of the transmural maldistribution of flow during the interval of restricted inflow in the presence of dilation of the coronary resistance vessels produced by the 5-s coronary artery occlusion. It is probable that nitroglycerin vasodilates these penetrating vessels directly; however, if wall tension is lowered due to a decrease in ventricular volume, a similar effect might be produced secondarily. 
The data reported in the present study indicate that in the presence of a proximal subtotal coronary artery occlusion which prevents significant increase in arterial inflow, coronary vasodilation induced by ischemia results in increased blood flow to the subepicardium at the expense of underperfusion of the subendocardium. In this experimental model, which may bear some analogy to the clinical situation of occlusive proximal coronary artery disease, nitroglycerin acted to correct this inhomogeneity of flow and restore the distribution of myocardial blood flow toward normal.

\section{ACKNOWLEDGMENTS}

The authors wish to acknowledge the valuable assistance provided by the following individuals: Mr. Kirby Cooper, Mr. Eric Fields, and Mr. James Ferrell for expert technical assistance; Mr. Michael Taylor and his staff of the Durham Veterans Administration Hospital Animal Care Facility; Mr. Donald G. Powell of the Durham Veterans Administration Hospital Medical Illustration Department; and Miss Brenda Clement and Mrs. Rosa B. Ethridge for secretarial assistance.

This work was supported in part by U. S. Public Health Service Grant HL-16438 from the National Heart and Lung Institute. Veterans Administration Program no. 0517-01.

\section{REFERENCES}

1. Kirk, E. S., and C. R. Honig. 1964. An experimental and theoretical analysis of myocardial tissue pressure. Am. J. Physiol. 207: 361-367.

2. Moir, T. W. 1972. Subendocardial distribution of coronary blood flow and the effect of antianginal drugs. Circ. Res. 30: 621-627.

3. Salisbury, P. F., C. E. Cross, and P. A. Rieben. 1963. Acute ischemia of inner layers of ventricular wall. $\mathrm{Am}$. Heart J. $66:$ 650-656.

4. Moir, T. W., and D. W. DeBra. 1967. Effect of left ventricular hypertension, ischemia and vasoactive drugs on the myocardial distribution of coronary flow. Circ. Res. 21: 65-74.

5. Griggs. D. M., Jr., and Y. Nakamura. 1968. Effect of coronary constriction on myocardial distribution of iodoantipyrine- ${ }^{131} \mathrm{I}$. Am. J. Physiol. 215: 1082-1088.

6. Fam, W. M., and M. McGregor. 1968. Effect of nitroglycerin and dipyridamole on regional coronary resistance. Circ. Res. 22: 649-659.

7. Winbury, M. M., B. B. Howe, and M. A. Hefner. 1969. Effect of nitrates and other coronary dilators on large and small coronary vessels: a hypothesis for the mechanism of action of nitrates. J. Pharmacol. Exp. Ther. 168: 70-95.

8. Bache, R. J., F. R. Cobb, and J. C. Greenfield, Jr. 1974. Myocardial blood flow distribution during ischemiainduced coronary vasodilation in the unanesthetized dog. J. Clin. Invest. $54:$ 1462-1472.

9. Debley, V. G. 1971. Miniature hydraulic occluder for zero blood flow determinations. J. Appl. Physiol. 31: 138-139.
10. Alexander, J. A., W. C. Sealy, and J. C. Greenfield, Jr. 1969. Improved technique for implanting electromagnetic flowmeter probes on the coronary artery. J. Appl. Physiol. 27 : 139-140.

11. Eckstein, R. W. 1957. Effect of exercise and coronary artery narrowing on coronary collateral circulation. Circ. Res. 5: 230-235.

12. Freeman, N. E. 1935. The effect of temperature on the rate of blood flow in the normal and in the sympathectomized hand. Am. J. Physiol. 113: 384-398.

13. Cobb, F. R., R. J. Bache, and J. C. Greenfield, Jr. 1974. Regional myocardial blood flow in awake dogs. J. Clin. Invest. 53 : 1618-1625.

14. Koberstein, R. C., D. E. Pittman, and F. J. Klocke. 1969. Right atrial admixture in coronary venous blood. Am. J. Physiol. 216: 531-535.

15. Bache, R. J., F. R. Cobb, and J. C. Greenfield, Jr. 1973. Effects of increased myocardial oxygen consumption on the coronary reactive hyperemia in the awake dog. Circ. Res. 33: 588-596.

16. Pauly, T. J., W. C. Zarnstorff, and N. Bittar. 1973. Myocardial metabolic activity as a determinant of reactive hyperaemia responses in the dog heart. Cardiovasc. Res. 7 : 90-94.

17. Olsson, R. A., and D. E. Gregg. 1965. Myocardial reactive hyperemia in the unanesthetized dog. Am. J. Physiol. 208: 224-230.

18. Fam, W. M., and M. McGregor. 1964. Effect of coronary vasodilator drugs on retrograde flow in areas of chronic myocardial ischemia. Circ. Res. 15: 355-365.

19. Williams, J. F., Jr., G. Glick, and E. Braunwald. 1965. Studies on cardiac dimensions in intact unanesthetized man. V. Effects of nitroglycerin. Circulation. 32: 767771.

20. Lee, S. J. K., Y. K. Sung, and A. J. Zaragoza. 1970 Effects of nitroglycerin on left ventricular volumes and wall tension in patients with ischaemic heart disease. Br. Heart J. 32: 790-794.

21. Rolett, E. L., P. M. Yurchak, W. B. Hood, Jr., and R. Gorlin. 1965. Pressure-volume correlates of left ventricular oxygen consumption in the hypervolemic dog. Circ. Res. $17: 499-518$.

22. Wood, J. E., J. Litter, and R. W. Wilkins. 1956. Peripheral venoconstriction in human congestive heart failure. Circulation. 13 : 524-527.

23. Winbury, M. M., B. B. Howe, and H. R. Weiss. 1971. Effect of nitroglycerin and dipyridamole on epicardial and endocardial oxygen tension-further evidence for redistribution of myocardial blood flow. J. Pharmacol. Exp. Ther. 176: 184-199.

24. Weiss, H. R., and M. M. Winbury. 1974. Nitroglycerin and chromonar on small-vessel blood content of the ventricular walls. Am. J. Physiol. 226: 838-843.

25. Cohen, M. V., and E. S. Kirk. 1973. Differential response of large and small coronary arteries to nitroglycerin and angiotensin. Autoregulation and tachyphylaxis. Circ. Res. 33: 445-453.

26. Winbury, M. M. 1971. Redistribution of left ventricular blood flow produced by nitroglycerin. An example of integration of the macro- and microcirculation. Circ. Res. 28 Suppl. $I$ : 140-147.

27. West, J. W., and S. V. Guzman. 1959. Coronary dilation and constriction visualized by selective arteriography. Circ. Res. $7: 527-536$ 